\title{
OXYGEN-PROPELLANT PLASMA THRUSTERS FOR CIS-LUNAR ELECTRIC PROPULSION MISSIONS
}

\author{
Robert H. Frisbee ${ }^{*}$ and James E. Polk ${ }^{* *}$ \\ Jet Propulsion Laboratory \\ California Institute of Technology \\ Pasadena, California \\ and
Alec D. Gallimore ${ }^{\dagger}$ and Colleen M. Marrese ${ }^{\dagger} \dagger$
University of Michigan
Ann Arbor, Michigan

\begin{abstract}
This paper presents an analysis of the mission benefits and technology requirements of electric propulsion thrusters designed to use oxygen $\left(\mathrm{O}_{2}\right)$ as propellant, and an overview of the status of current research in this area. Such engine technology, when used in solar or nuclear electric propulsion transfer vehicles, could enable the use of lunar-produced oxygen propellant as a means of dramatically reducing the mass of vehicles and propellants required to support the build-up of a lunar base. It is found that there are mass benefits, but these benefits are countered somewhat by long trip times due to the low electric-to-jet power efficiency of $\mathrm{O}_{2}$-propellant electric thrusters.
\end{abstract}

\section{INTRODUCTION}

This paper presents an analysis of the technology status and requirements, and mission benefits of electric propulsion thrusters designed to use oxygen $\left(\mathrm{O}_{2}\right)$ as propellant. Such engine technology, when used in solar or nuclear electric propulsion transfer vehicles, could enable the use of lunar-produced oxygen

\footnotetext{
* Senior Staff, Member AIAA.

** Group Supervisor, Member AIAA.

$\dagger$ Associate Professor, Member AIAA.

t† Ph.D. Candidate.
}

propellant as a means of dramatically reducing the mass of vehicles and propellants required to support the build-up of a lunar base.

Conventional electric propulsion technology employs thruster designs and materials technologies that limit propellant choices to those that are inert or reducing (e.g., $\mathrm{Xe}, \mathrm{H}_{2}, \mathrm{NH}_{3}, \mathrm{Li}$ ). By contrast, use of a highly-oxidizing propellant plasma introduces several unique challenges to the design and operation of an electric propulsion thruster. Cathodes which are typically used employ a thermionic emitter that can be poisoned easily in the presence of oxygen. Furthermore, the anode of an electric propulsion device can become coated with an oxide film that eventually increases the surface resistance until there is no longer a current conduction path in the thruster electrical circuit.

Similarly, integration of these thrusters into a vehicle designed for transportation from low Earth orbit (LEO) to low lunar orbit (LLO) involves tradeoffs between propellant resupply from Earth versus that from the Moon. For example, the greater the utilization of lunar propellant, the more hydrogen that must be imported from Earth to supply a high-thrust chemical or nuclear-thermal stage used to ferry $\mathrm{O}_{2}$ propellants from the lunar surface to LLO. Thus, there will tend to be an optimum degree of lunar- $\mathrm{O}_{2}$ utilization that minimizes the total mass delivered to LEO from Earth. 
This paper will first present an overview of the status of current research in the area of thrusters designed to use $\mathrm{O}_{2}$, and then describe the mission benefits of electric propulsion using lunar-produced $\mathrm{O}_{2}$ propellant.

\section{STATUS OF CURRENT RESEARCH ON O2-PROPELLANT ELECTRIC THRUSTERS}

Hall thrusters, specifically stationary plasma thrusters (SPT), have been under development for the past 30 years 1,2 and have flown on over 50 Russian spacecraft. Because they offer significant advantages over chemical engines and other electric propulsion systems, 3 the most important being lower cost, they are currently being integrated into western spacecraft systems for station-keeping, repositioning, and orbit transfer missions. Recent advances in solar cell technology and electronics are increasing the power available to spacecraft propulsion systems which enable the use of high-power electric thrusters for spacecraft. The high-power thrusters could then be used as the primary spacecraft propulsion for orbit-raising and orbit transfer missions. 4

Electric propulsion systems operating on oxygen propellant offer advantages over thrusters that employ an inert gas propellant for both ground- and space-based applications. Oxygen plasma accelerators are commonly used as plasma sources for oxide and metallic film deposition and substrate cleaning. With the recent initiative to build smaller, faster, less expensive spacecraft, In-Situ Resource Utilization (ISRU) is being explored for lunar and Mars sample return missions because the lunar surface contains significant amounts of oxygen-containing minerals and the Martian atmosphere contains carbon dioxide. $5,6,7$ Because the mission $\Delta \mathrm{V}$ capability of most spacecraft is typically limited by the amount of on-board propellant, significant mission savings are possible with ISRU by increasing spacecraft capability and decreasing launch costs. However, the disadvantages of oxygenpropellant Hall thrusters are low efficiency and short lifetimes of the high temperature components that oxidize quickly in the hostile plasma environments generated by the thruster.

Hall and ion oxygen-propellant thruster development for ground-based applications has been active at several institutions in the United States, while research into the performance of these plasma sources for spacecraft propulsion systems has been active primarily at the Moscow Aviation Institute (MAI) in Russia. A 47-mm laboratory model Hall thruster tested at the MAI that demonstrated performance efficiency of $16 \%$ at a propellant flow rate of $1.2 \mathrm{mg} / \mathrm{s}, 300 \mathrm{~V}$, and $1.3 \mathrm{~A}$ with xenon propellant, and offered $5 \%$ efficiency at $300 \mathrm{~V}$ and $2.4 \mathrm{~A}$ with oxygen. The thruster efficiency exceeded $30 \%$ at $3 \mathrm{mg} / \mathrm{s}, 300 \mathrm{~V}$, and $2.7 \mathrm{~A}$ on xenon but was not tested at such high propellant flow rates on oxygen. The highestpower operating point for the oxygen propellant was at $1.22 \mathrm{mg} / \mathrm{s}, 360 \mathrm{~V}$, and $2.3 \mathrm{~A}$ where the efficiency was only $6.6 \%$. With increasing power levels and improved thruster design, the efficiency of the thruster operating with oxygen propellant is expected to increase, although high power oxygen thruster performance tests and lifetime tests have not yet been performed on Hall thrusters. It is believed that the upper limit on the efficiency will be fairly low, $\sim 20 \%$, because of both negative ion generation and frozen flow loses.

Along with low efficiency, a thruster operating on oxygen is susceptible to short lifetimes because of the hostile nature of oxygen. The lifetime of the thruster is limited by cathode and anode lifetime. While typical Hall thrusters operating on xenon have demonstrated lifetimes in excess of 7000 hours, ${ }^{6}$ oxidation of the cathode and anode are expected to reduce thruster lifetime significantly. The anode lifetime problem is primarily a materials issue. Anode material optimization is currently being investigated. If a hollow cathode is employed with a Hall 
thruster, additional inert gas propellant is required through the cathode to protect the electron emitter from the oxygen. The cathode propellant is typically an inert gas. Even with an inert gas propellant flowing through the cathode, the lifetime of the cathode is expected to be limited to several tens of hours. While this short lifetime is acceptable for groundbased systems, several thousand of hours are required for trans-lunar cargo and interplanetary vehicles. Therefore, the development of a cathode that can operate for the required lifetimes is the primary focus of the project to develop a Hall thruster that can operate on oxygen.

The ideal cathode for this thruster will operate at low temperatures without propellant. The field emission cathodes are the primary candidates for use in oxygen Hall thrusters. These cathodes operate near room temperature without additional propellant. However, the sharp emitting tips will degrade in shape and therefore performance in the hostile environment created by the thruster. The cathode lifetime then also becomes a materials issue. Carbide coated molybdenum field emission arrays have been targeted in this investigation because of their chemical inertness, high binding energies (melting point), and low operating voltages. ${ }^{9}$ Typical emitters operate notoriously poorly outside of the ultrahigh vacuum regime, while the carbide emitters have demonstrated operation in 7 milliTorr oxygen environments. 9
With improved thruster design, and anode and cathode materials with lifetimes in excess of 6000 hours and efficiency $20 \%$, it is possible to use oxygen Hall thrusters for spacecraft propulsion. Lunar and Mars missions will require a specific impulse $\left(\mathrm{I}_{\mathrm{sp}}\right)$ range between 1600 to $2400 \mathrm{lbf}-\mathrm{s} / \mathrm{lbm}$. The predicted oxygen thruster performance in this regime is included in Table 1 below for a 100mm class thruster.

\section{MISSION ANALYSES}

As discussed above, there is the potential for dramatic reductions in the mass that must be launched from Earth to support various space missions when ISRU is employed to provide propellants for sample return or piloted lunar and Mars missions. For example, for a typical chemical oxygen/ hydrogen $\left(\mathrm{O}_{2} / \mathrm{H}_{2}\right)$ propulsion system, operating at an oxidizer-to-fuel $(\mathrm{O} / \mathrm{F})$ ratio of 6 , $86 \%$ (i.e., 6/7) of the total propellant mass can be supplied from $\mathrm{O}_{2}$ made on the Moon or Mars. Thus, a considerable mass savings can be realized for the return leg of a mission (although this mass savings will be offset by the mass of the $\mathrm{O}_{2}$-production facility). Furthermore, additional lunar- or Marsproduced $\mathrm{O}_{2}$ carried back to low Earth orbit (LEO) can be used for the next outbound mission. However, for any given mission, there will be a complex trade-off between the amount of materials supplied from Earth and the amount of ISRU materials employed in order to minimize the total mission cost.

Table 1. Predicted Oxygen-Propellant Thruster Performance (100-mm Class Thruster)

\begin{tabular}{|c|c|c|c|c|c|}
\hline $\begin{array}{c}\text { Voltage } \\
(\mathrm{V})\end{array}$ & $\begin{array}{c}\text { Current } \\
(\mathrm{A})\end{array}$ & $\begin{array}{c}\text { Thrust } \\
(\mathrm{mN})\end{array}$ & $\begin{array}{c}\text { Isp }_{\text {sp }} \\
\left(\mathrm{lb}_{\mathrm{f}}-\mathrm{s} / \mathrm{lb}\right)\end{array}$ & $\begin{array}{c}\text { Efficiency } \\
(\%)\end{array}$ & $\begin{array}{c}\text { Specific Mass } \\
(\mathrm{kg} / \mathrm{kW})\end{array}$ \\
\hline 500 & 6.0 & 77 & 1600 & 20 & 1.20 \\
620 & 6.2 & 80 & 2000 & 22 & 0.91 \\
740 & 6.4 & 83 & 2400 & 24 & 0.74 \\
\hline
\end{tabular}


For simplicity, we will use as our figure of merit the total initial mass in LEO (IMLEO) that must be supplied from the Earth; this number relates indirectly to the overall mission cost through the Earth-to-LEO launch cost (i.e., $\$ / \mathrm{kg}$ ) assumed for the mission. For these mission analyses, we will compare the IMLEO of an all-chemical $\left(\mathrm{O}_{2} / \mathrm{H}_{2}\right)$ and combined chemical and $\mathrm{O}_{2}$-electric propulsion system designed to ferry cargo to a lunar base.

\section{Mission Scenario}

For the all-chemical system, an orbit transfer vehicle (OTV) is used to ferry cargo and supplies between LEO and low lunar orbit (LLO); a separate lunar transfer vehicle (LTV) (derived from the OTV) is used travel between LLO and the lunar surface. In the combined chemical/electric propulsion option, a solar electric propulsion (SEP) vehicle is used as a low thrust-to-weight (T/W) OTV; the high-T/W chemical LTV is retained for landing/takeoff from the Moon. Finally, an all-chemical system is used to deliver crewed modules from LEO to the lunar surface and back to LEO.

\section{Vehicle Sizing}

The $\Delta \mathrm{V}$ and scaling assumptions used for the chemical OTV and LTV, and $\mathrm{O}_{2}$ propellant SEP OTV are given in Tables 2 and 3 , respectively. For a re-usable chemical OTV, an aeroshell is used to reduce the LLO-to-LEO $\Delta \mathrm{V}$, although at the mass cost of the aeroshell (e.g., $15 \%$ of the vehicle mass aerobraked into LEO). Similarly, the chemical LTV has added engines and landing legs $(0.8 \%$ of the landed mass, corresponding to $5 \%$ of the lunar weight). Each vehicle has a "tankage factor," corresponding to the mass of systems (tankage, feed, pressurization, etc.) that scale as the mass of stored propellant $\left(\mathrm{M}_{\mathrm{p}}\right)$. Finally, the LTV has additional $\Delta \mathrm{V}$ added for the landing step to allow contingency for maneuvering and final approach to the lunar base landing site.

The SEP OTV power (solar array), power management and distribution (PMAD), and thruster systems have a specific mass $(\mathrm{kg} / \mathrm{kW}$ e) such that their masses scale as the total "bus" power $\left(\mathrm{P}_{\mathrm{e}}\right)$. Note that we have assumed the use of a "direct-drive" SEP system, where the power (and voltage) output from the solar arrays is fed directly to the thruster. This has the effect of dramatically reducing the PMAD mass as compared to that required for an ion thruster. (By comparison, an advanced solar array could directly supply the roughly $500-740 \mathrm{~V}$ required for the Hall thrusters, whereas significant power processing is required for the kilovolt input power required by an ion thruster.)

Also, it is important to consider the overall power flow in an electric propulsion vehicle and its impact on total system mass. For example, if we assume a bus electric power $\left(\mathrm{P}_{\mathrm{e}}\right)$ of $1 \mathrm{MW}$, the mass of the power system is 16.0 metric tons (MT), and the PMAD system is $1.1 \mathrm{MT}$. However, the thruster specific mass values given in Table 1 correspond to the power actually entering the thruster; thus, only $0.9 \mathrm{MW}_{\mathrm{e}}$ of power enter the thruster (because the PMAD system is only $90 \%$ efficient), so the thruster's "effective" system-level specific mass is only $1.08 \mathrm{~kg} / \mathrm{kW} e$ (for the $1600 \mathrm{lbf}-\mathrm{s} / \mathrm{lb}_{\mathrm{m}}$ thruster) based on an initial $1 \mathrm{MW}_{\mathrm{e}}$ of $\mathrm{P}_{\mathrm{e}}$. Note also that because of the thruster's limited lifetime (assumed here to be 6,000 hours), additional sets of thrusters must be added to the vehicle, which increases the thruster's effective specific mass further.

For the SEP system, the overall electric propulsion thruster "jet" power is the product of the initial bus electric power and the PMAD and thruster efficiencies $(\eta)$ :

$$
\mathrm{P}_{\text {jet }}=\mathrm{Pe}_{\mathrm{e}} \cdot \eta \mathrm{PMAD} \cdot \eta \text { Thruster }
$$

Trip time for the low-T/W SEP OTV constantthrust LEO-to-LLO or LLO-to-LEO trajectory is found by dividing the propellant mass required for a given leg of the trip by the propellant mass flow rate (e.g., $\mathrm{kg} / \mathrm{s}$ ) through the thrusters. An additional 5\% of the trip time is added to represent shadowing of the electric 
propulsion vehicle (during which time the vehicle simply coasts) by the Earth or Moon.

Finally, the OTV employs additional propellant tankers to transport propellant for the LTV $\left(\mathrm{H}_{2}\right.$ only in the lunar- $\mathrm{O}_{2}$ option). Similarly, the LTV uses an additional $\mathrm{O}_{2}$ tanker to transport lunar $\mathrm{O}_{2}$ from the surface of the Moon to the OTV in LLO; a similar $\mathrm{O}_{2}$ tanker is used on the OTV to transport lunar $\mathrm{O}_{2}$ from $\mathrm{LLO}$ to LEO. The $\mathrm{H}_{2}$ tanker has a tankage fraction of $25 \%$; the $\mathrm{O}_{2}$ tanker has a tankage fraction of $5 \%$

Table 2. Vehicle $\Delta \mathrm{V}$ Budget

\begin{tabular}{|l|c|c|}
\hline Vehicle & Chem & SEP \\
\hline LEO->LLO & $\begin{array}{c}4.10 \mathrm{~km} / \mathrm{s} \\
\text { LLO->LEO }\end{array}$ & $\begin{array}{l}1.15 \mathrm{~km} / \mathrm{s}^{*} \\
8.10 \mathrm{~km} / \mathrm{s} / \mathrm{s}\end{array}$ \\
\hline LLO->MOOn & $\begin{array}{l}2.15 \mathrm{~km} / \mathrm{s} \\
\text { Moon->LLO }\end{array}$ & \\
\hline
\end{tabular}

* Aerobraked

Table 3. Vehicle Scaling Equations

\begin{tabular}{|c|c|c|}
\hline Chem Vehicles & OTV & LTV \\
\hline$\overline{\text { Fixed Mass (MT) }}$ & $\overline{1.50}$ & $\overline{1.77}$ \\
\hline Tankage (\% of $\left.\mathrm{M}_{\mathrm{p}}\right)$ & 13.5 & 13.5 \\
\hline $\mathrm{I}_{\mathrm{sp}}\left(\mathrm{lbf}-\mathrm{s} / \mathrm{lb}_{\mathrm{m}}\right)$ & 460 & 460 \\
\hline $\mathrm{O} / \mathrm{F}$ & 6 & 6 \\
\hline Aeroshell Factor & 0.15 & \\
\hline Landing Legs Factor & & 0.008 \\
\hline SEP Vehicle & \multicolumn{2}{|c|}{ OTV } \\
\hline$\overline{\text { Fixed Mass (MT) }}$ & \multicolumn{2}{|c|}{2.0} \\
\hline Tankage (\%Mp) & \multicolumn{2}{|c|}{5.0} \\
\hline EP System: & $\mathrm{kg} / \mathrm{kW}_{\mathrm{e}}$ & Eff. $(\%)$ \\
\hline Solar Array & 16.0 & \\
\hline PMAD & 1.1 & 90 \\
\hline Thrusters & See & ble 1 \\
\hline
\end{tabular}

\section{Results of the Mission Analyses}

Results of the mission analyses are shown in Figures 1 and 2. Two mission classes were considered; the first is delivery of 43.8 MT of cargo to the lunar surface using either an all-chemical system or an SEP OTV and chemical LTV system. The other mission considered is an all-chemical system delivering a 14.1-MT piloted module to the lunar surface and returning it to LEO. For both mission types, there is the option of using only propellants from Earth, or of using lunar $\mathrm{O}_{2}$. In the latter case, lunar $\mathrm{O}_{2}$ is used in the LTV and in the OTV for its return to LEO; in addition, some lunar $\mathrm{O}_{2}$ is returned to LEO for use in the next LEO-to-LLO OTV mission. In this case, only $\mathrm{H}_{2}$ from Earth is transported to LLO for use by the chemical LTV.

In order to simulate a life-cycle cost (mass) per mission, we have used an "amortized" IMLEO which includes permission payloads and consumables masses (e.g., propellants, Hall thrusters) as well as initial system set-up masses (e.g., vehicle dry weights) amortized over a 10-mission life cycle (assuming that each reusable vehicle has a life of 10 missions). In addition, the mass of a oneway cargo delivery mission is included in the lunar- $\mathrm{O}_{2}$ options and amortized over the 10 missions to simulate the cost (mass) of initially establishing a lunar- $\mathrm{O}_{2}$ production facility on the Moon.

These analyses illustrate the impact that the low efficiency of the $\mathrm{O}_{2}$-propellant Hall thrusters have on mission performance. In order to achieve a 1-year round-trip delivery schedule, high powers (many $M W_{e}$ ) are required; the mass of the solar arrays, $\mathrm{PMAD}$, and thrusters (whose masses depend on $\mathrm{P}_{\mathrm{e}}$ ) adversely impacts the overall IMLEO of the SEP OTV. Relaxation of the trip time requirement to 2 years (roughly equivalent to doubling the thruster efficiency for a 1-year trip time) has a significant benefit. Thus, a goal of thruster development should be to increase efficiency. 


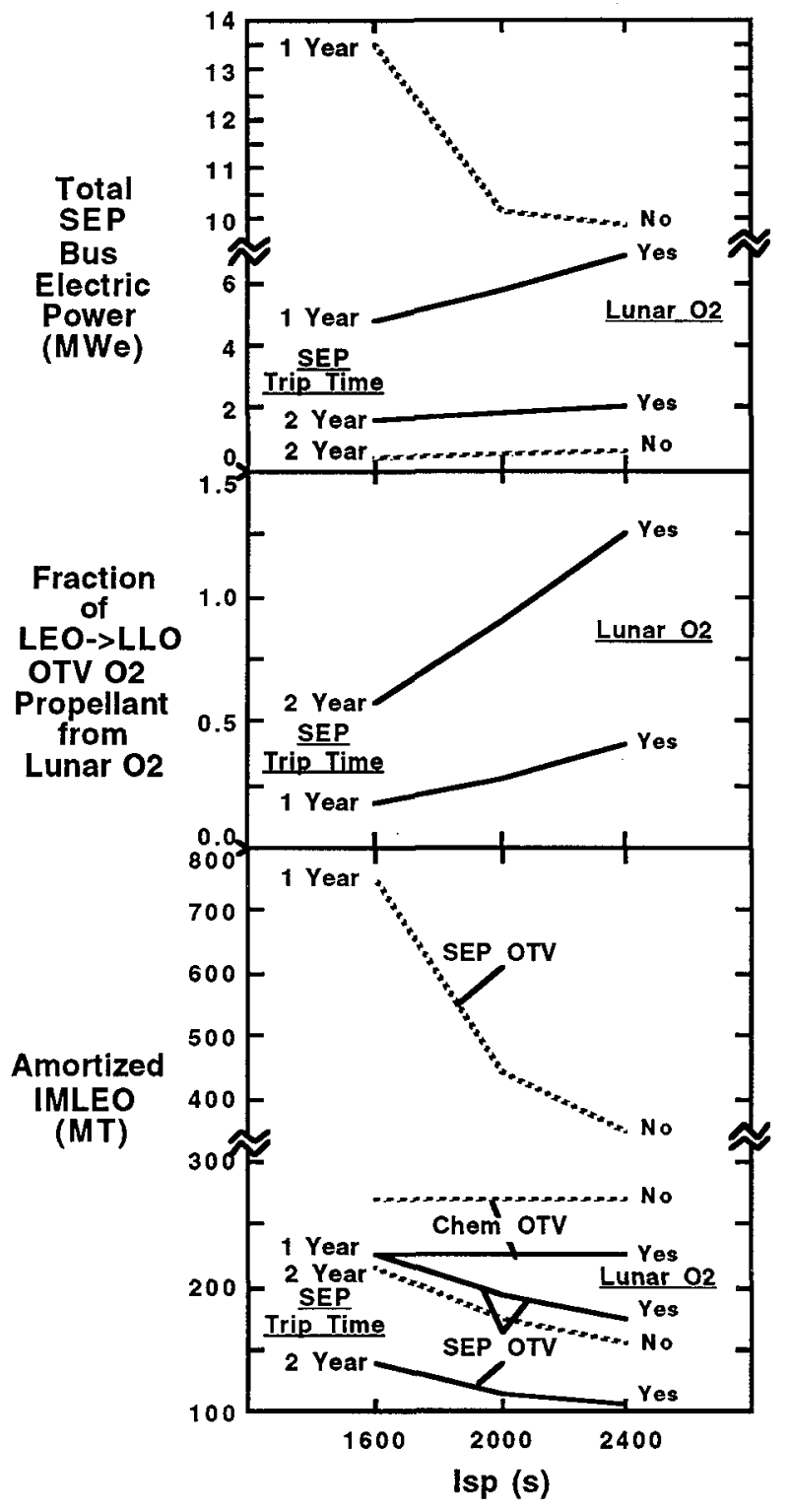

Figure 1. Amortized IMLEO, Fraction of LEOto-LLO OTV Oxygen Propellant Supplied from the Moon, and Bus Electric Power as a Function of SEP OTV Specific Impulse for the Cargo Delivery Mission

Another interesting result is the increased SEP OTV power required for the lunar- $\mathrm{O}_{2}$ option as specific impulse increases. This is due in part to the inverse relationship between $I_{S p}$ and trip time for a given power; however, it is also indicative of the progressively greater fraction of the LEO-to-
LLO $\mathrm{O}_{2}$ propellant that can be carried from LLO-to-LEO as the Isp increases. In fact, for the 2-year trip time, $2400-\mathrm{lbf}_{\mathrm{f}} \mathrm{s} / \mathrm{lb} \mathrm{b}_{\mathrm{m}} \mathrm{I}_{\mathrm{sp}}$ case, $26 \%$ more propellant than that needed for the LEO-to-LLO step can be delivered. Thus, there can be a significant benefit from highefficiency, lunar- $\mathrm{O}_{2}$ Hall thruster systems operating at moderately high $\mathrm{I}_{\mathrm{Sp}}$.

\section{CONCLUSIONS AND RECOMMENDATIONS}

Lunar- $\mathrm{O}_{2}$ electric propulsion systems hold the potential for significant reductions in IMLEO for future orbit transfer operations in cis-lunar space. However, the projected low electric-to-jet power conversion efficiencies of these devices is a serious issue that should be addresses by future technology development efforts. Finally, we recommend that the mission performance of these systems be reevaluated as improved thruster data become available.

\section{ACKNOWLEDGMENT}

The research described in this paper was carried out by the Jet Propulsion Laboratory, California Institute of Technology, under a contract with the National Aeronautics and Space Administration.

\section{REFERENCES}

1. Bober, A.S., et al., "State of Work on Electrical thrusters in USSR," Proceedings of the 22nd International Electrical Propulsion Conference, Viareggio, Italy, October 1991.

2. Belan, N.V., Kim, V.P., Oransky, A.I., and Tikhonov, V.B., "Stationary Plasma Thrusters," Kharkov Aviation Institute, Kharkov 1989. (In Russian). 


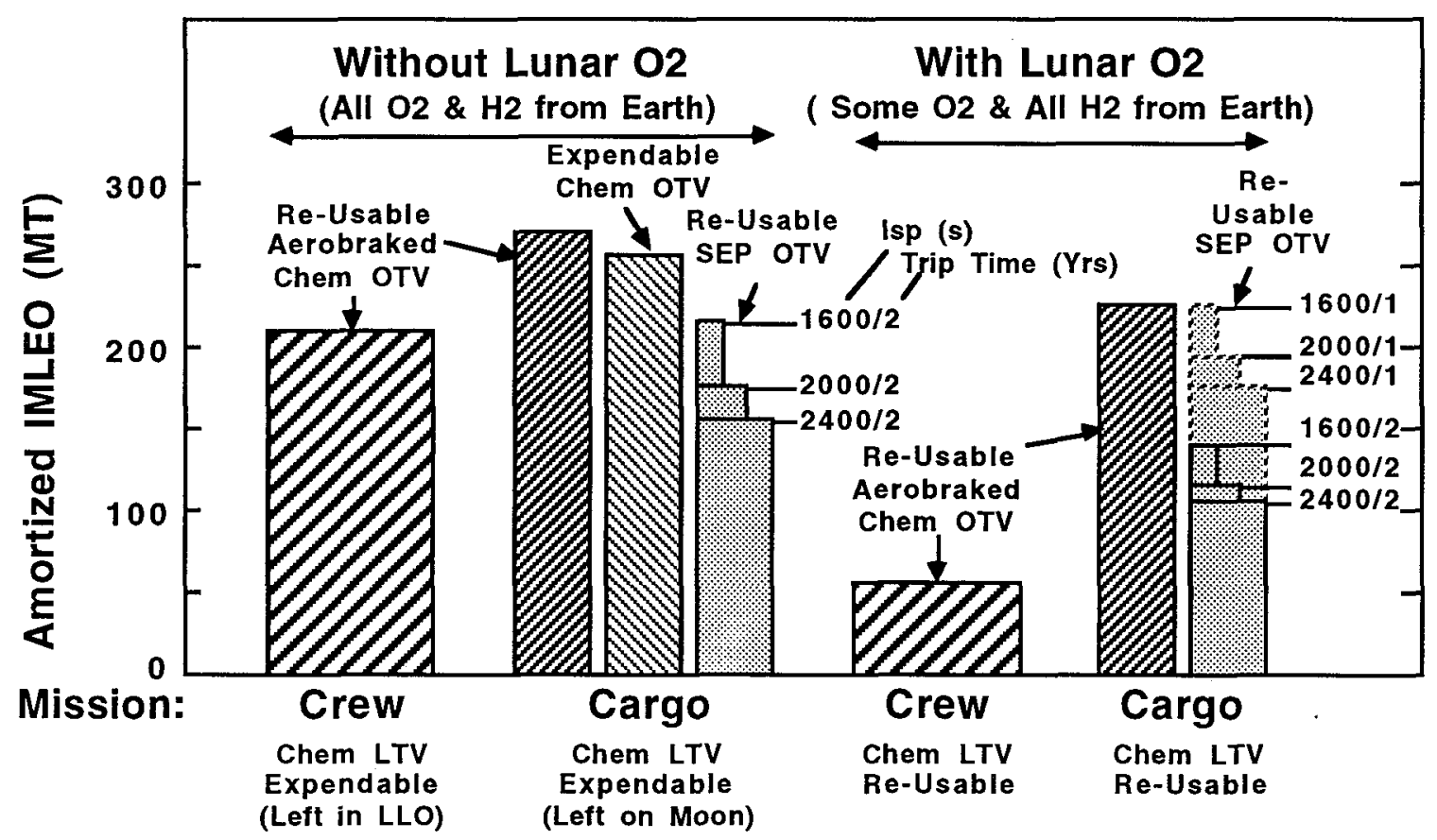

Figure 2. Total Amortized Initial Mass in LEO (IMLEO) for the Various Cargo and Crewed Missions, With and Without Use of Lunar Oxygen

3. Cassady, R.J., King, D.Q., Meckel, N.J., "Repositioning Benefits Comparison for Near-Term Electric Propulsion Technology," AIAA Paper AIAA 94-3002, Joint Propulsion Conference, Indianapolis IN, June 1994.

4. Arkhipov, B.A., Veselovsorov, A.N., Kudryavtsev, S.S., et al., "Development and Investigation of SPT Models with Increased Power," IAF Paper IAF 93S.5.488.

5. Frisbee, R.H., and Jones, R.M., "An Analysis of Propulsion Options for Transport of Lunar Materials to Earth Orbit," AIAA Paper AIAA 83-1344, Joint Propulsion Conference, Seattle WA, June 1983.

6. Carlton, C.A, McKay, D.S., "Lunar Oxygen Production --Ground Truth and Remote Sensing," AIAA Paper AIAA 952792, Joint Propulsion Conference, San Diego CA, July 1995.
7. Coons, S.C., Curtis, R.M., McLain, C., Williams, J.D., Warwick, R., Bruckner, A.P., "In Situ Propellant Production Strategies and Applications for a Low-Cost Mars Sample Return Mission," AIAA Paper AIAA 95-2796, Joint Propulsion Conference, San Diego CA, July 1995.

8. Arhipov, B.A., Bober, A.S., Gnizdor, R.Y., Kozubsky, K.N., Korakin, A.I., Maslennikov, N.A., Pridannikov, S.Y., "The Results of the 7000-Hour SPT-100 Life Testing," Proceedings of the 24th International Electric Propulsion Conference, Moscow, Russia, September 1995.

9. Marrese, C.M., Gallimore, A.D., Mackie, W.A., and Evans, D.E., "The Design of a Cathode to Operate in an Oxygen-rich Environment," Space Technology and Applications International Forum, Albuquerque NM, January 1997. 